\title{
From Chaos to Normalization and Deconfinement: What did the Pandemic Unveil in Youth Residential Care
}

\author{
Helena M. Carvalho ${ }^{1,2}$ (D) Catarina P. Mota ${ }^{1,3}$ (D) $\cdot$ Beatriz Santos $^{2}\left(\mathbb{D} \cdot\right.$ Mónica Costa $^{1}$ (D) Paula M. Matos ${ }^{1,2}$ (D)
}

Accepted: 8 December 2021

(c) The Author(s), under exclusive licence to Springer Science+Business Media, LLC, part of Springer Nature 2021

\begin{abstract}
The conditions imposed by the Covid-19 outbreaks forced residential care (RC) facilities to experience new challenges and to adopt new practices. The aim of the current study is to analyze how RC facilities have experienced and managed confinement during the 1st wave of the pandemic. A thematic analysis of 20 semi-structured interviews were conducted with professionals responsible for managing crisis in RC facilities. The main implications of the confinement measures on $\mathrm{RC}$ dynamics and relations were organized in three major themes: Chaos, novelty and organization; reinventing normalization and deconfinement. The pandemic exposes the structural weaknesses of RC, namely mobility of human resources, scarcity of supportive networks, and fragilities in providing comprehensive and integrative care. These factors need to be considered when addressing risk/vulnerability and discussing best practices and policies on child/youth welfare domain. Future studies should explore representations of important key actors as youth, families and other professionals from youth care.
\end{abstract}

Keywords Residential care $\cdot$ Pandemic $\cdot$ Youth $\cdot$ Professionals $\cdot$ Qualitative analysis

According to the World Health Organization, COVID-19 outbreak reached pandemic status on March 11, 2020. 1 year after around 158 million cases had been reported and 3.3 million people have sadly lost their lives (WHO, 2021). The consequences of this unpredicted virus have largely surpassed the number of people infected by the disease. International organizations have been reporting the harmful economic and social consequences of an unprecedented international lockdown, namely on children, risking decades of progress on children's health, education and other priorities (Ingram, 2020, p. 3). If it is still early to calculate the definitive damage, a growing body of research has been stressing, as in previous pandemics, how this virus has been unequally affecting people, especially those who were already in vulnerable situations given their economic, social or health status (e.g., Ahmed et al., 2020).

Paula M. Matos

pmmatos@fpce.up.pt

Centre for Psychology, University of Porto, Porto, Portugal

2 Faculty of Psychology and Education Sciences, University of Porto, Alfredo Allen Street, 4200-135 Porto, Portugal

3 University of Tras-os-Montes and Alto Douro, Vila Real, Portugal
In the psychological arena, additional concern has been devoted to the mental health issues of the general population and particularly in health care workers. A literature review conducted on 28 publications on the subject have shown subsyndromal mental health problems - like anxiety, depression, stress, and sleep disturbances - to be common responses to the COVID-19 pandemic (Rajkumar, 2020). For some authors, the potential for reaching a true mental health crisis, namely in highly vulnerable populations (Thomson et al., 2020) and in countries with high caseloads, is real (Dong \& Bouey, 2020). Although youngsters are not particularly at risk of severe physical illness due to Covid19 , public health and mitigation measures might have unintended consequences for their health and well-being. School closures and reduction in health and social staff involved in safety nets will disproportionately affect children that were already in vulnerable situations (Wong et al., 2020). This is particularly relevant regarding children/youth living in outof-home care (Silliman Cohen \& Bosk, 2020; UN, 2020). If globally children/youth are particularly vulnerable to sustained stressors (Courtney et al., 2020), the high prevalence of mental health symptoms, pain-based behaviors, and risk trajectories among this population (Anglin, 2004; Costa et al., 2019; Tarren-Sweeney, 2008), warrants special consideration. Additionally, social distancing measures imply, 
for the great majority of institutionalized children and youth, the interruption or reduction of the contact with parents and/ or other relatives, as well as the delay in court assessment or other services that hinder life projects (Galvin \& Kaltner, 2020). In extremis, a growing number of institutions are being closed due to the pandemic around the world, and children are being sent back to their communities without proper monitoring or reassurance of their safety (Goldman et al., 2020; Wilke et al., 2020). In Portugal, closure turns out not to be the case for the great majority of the RC facilities. Instead, since the middle of March, it was declared the temporary suspension of all types of visits and exits of children and young people living in RC (NISS, 2020b). Exceptional cases that include child and youth reintegration in the family were considered with proper monitoring from the $\mathrm{RC}$ team and with the social security services case manager (NISS, 2020b). This 3-month period brought additional challenges to RC functioning, especially in a country with one of the highest rates of children and youth under this type of measure (Delgado \& Gersão, 2018). It is estimated that almost 7.046 children and adolescents were under any type of RC in 2019, with most of them (87\%) in non-therapeutic (generalist) RC facilities (NISS, 2020a). The great majority of children and adolescents was confined from March 15th to May 25th 2020 (NISS, 2020c).

Additional stressors to the RC system included dealing with relational constraints due to restricting family visits, human resources management and the uncertainty imposed by the unpredictability of the pandemic evolution. Also, in this scenario, staff, being the most important agents to maintain stability in the residential care (RC) settings, were particularly vulnerable to overwhelming workload due to reductions on human resources resulting from colleague's sick leave, family assistance, or situations of prophylactic isolation (NISS, 2020c, 2020d). The unprecedented conditions imposed by the pandemic forced institutions to adopt different practices and to experience new challenges. If this exceptional period could work as a social laboratory for observing how services and practices integrated and responded to crisis, it can also open space for the production of recommendations through problematizing the processual role of previous RC structural constraints on the quality of the responses (e.g., mobility of human resources, scarcity of supportive networks and fragilities in providing comprehensive and integrative care). Additionally, given the scarce literature on the implications of the pandemic in youth out of home care services, this study will focus on professionals' narratives about the main implications of the 1st lockdown on $\mathrm{RC}$ functioning and the provision of care. A qualitative approach was considered most adequate given its added value for understanding services' responses to the pandemics and for producing knowledge that could inform tailored practices and policies (Vindrola-Padros et al., 2020).
The main aim of this study is to analyze how RC facilities in Portugal have experienced and managed during the pandemics' imposed confinement. By gaining a deeper understanding on the system's plasticity, this study could ultimately contribute for understanding how the pandemic exposed (prior) RC fragilities. Also, by addressing the implications of the pandemic and restriction measures, this study will contribute to the problematization of the risk assessment during crisis management on vulnerable populations (UN, 2020), namely in a country where most of the children/youth in out-of-home care live in RC settings with institutionalization periods that range from less than 1 year to 6 or more years ( $\mathrm{M}=3.4$ years) (NISS, 2020).

This study is part of an action research project CareME that is currently being implemented with caregivers working in RC settings in Portugal. The project results from the collaboration of two universities from the North of Portugal (Faculty of Psychology and Education Sciences of University of Porto and University of Tras-os-Montes and Alto Douro) and includes the participation of 21 of the total of $24 \mathrm{RC}$ facilities operating in the Porto district.

\section{Method}

\section{Procedure}

All RC facilities that accepted to participate in the CareME project $(\mathrm{N}=21)$ were contacted and the study goals and procedures were explained. Only one RC declined the invitation to participate in the present study because the institution was facing internal restructuring. The interviews were conducted in approximately 1 month (from June 16th to July $21 \mathrm{st}$ ). The initial contact was established with professionals with responsibilities for technical decisions in the RC facilities, namely directors (D). Each institution selected the participant/participants for the study considering their active role on management and time spent with children/youth during confinement. Interviews were conducted (and recorded) on an online platform (specifically Zoom). Participants signed an informed consent document. During the verbatim transcription of the interviews, participants' and RC facilities' identification was anonymized. Audio registrations were eliminated after the conclusion of transcription process. Interviews were held for 17 to $1 \mathrm{~h}$ and $19 \min (\mathrm{M}=47.7$; $\mathrm{DP}=16.89$ ). The study received ethical approval from the authors' University Ethics Committee.

\section{Participants}

The study included a purposeful sampling (Patton, 2002) of 22 professionals from 20 different RC institutions. Most of the semi-structured interviews $(n=18)$ were conducted with one representative of each RC facility; in three cases, 
the interviews were conducted with 2 representatives per institution, since both interviewees assumed decision-making positions in distinct moments of the pandemic. Most interviewees were directors $(n=18)$, followed by technical team staff $(n=3)$ and one educative team staff.

Twenty of the 22 participants were female, and ages ranged between 30 and $69(\mathrm{M}=43.87, \mathrm{SD}=9.21)$. Participants had a minimum of 1.5 years of work experience in RC settings and a maximum of 30 years $(\mathrm{M}=14.93, \mathrm{SD}=7.71)$. Participants' professional background included social service $(n=14)$, social education $(n=4)$, psychology $(n=4)$ and sociology $(n=1)$.

\section{Measure}

The semi-structured interview, $R C$ and Covid-19 Interview was originally developed for the current study to capture the main implications of the pandemic on RC facilities. The interview guide included questions regarding professional and demographic information (e.g., age, years of experience, professional background), an introductory sentence (the pandemic suddenly changed our life) and the following 8 questions: (1) We would like to know your opinion about the major implications of the pandemic and confinement on: (a) the work developed in the RC settings with youth, families and staff and (b) staff's work-family conciliation (e.g., changing shifts, hygiene procedures, inhibition of contacts with family/friends); (2) Can you identify distinctive phases/ moments in this process of dealing with the pandemic consequences and constraints? (3) What were the most difficult moments? (identify challenges/difficulties) and what has surprised you the most?; (4) Can you identify facilitative factors in dealing with the implications of confinement?; (5) What were the most important lessons that we can learn from these unexpected times?; (6) What were the major implications of the pandemic for youth, namely in their emotional adjustment and adaptation to RC; (7) After all that we have lived, what changes have been made regarding $\mathrm{RC}$ and what do you consider important to maintain after the end of the confinement? (8) Do you want to add any more information?

\section{Data Analysis}

Considering the qualitative and exploratory nature of the study, a thematic analysis approach was conducted. This method was chosen considering that its theoretical flexibility is particularly valuable for exploring people's experiences and the construction of a specific phenomenon (Braun \& Clarke, 2006; Clarke \& Braun, 2013), such as the one lived during the pandemic. The analytical process was conducted following the nonlinear proposal of Braun and Clarkes' (2006) six phases of data analysis and reporting, including codes and patterns' identification, themes generation and results presentation. A Ph.D. researcher from CareME project, with experience in qualitative analysis, was responsible for conducting the interviews and analyzing the data. The active involvement of the researcher in both moments was crucial for enhancing familiarization with data (Braun \& Clarke, 2006; Clarke \& Braun, 2013) and for effectively eliciting the exploration of participants' ideas and discourses that could ultimately contribute to a more inclusive and comprehensive coding process. Additionally, two other members from CareME project with vast experience in child welfare studies, worked as peer debriefers and were actively involved in the analytic process, discussing, and reviewing data analysis from code generation to themes description. This was a dialogical, reflexive, and cyclical process that required returning to the data during themes organization and the identification of distinctive "patterns of implicit or explicit content" (Joffe, 2011, p. 209). In this sense, the coding process ranged between inductive and deductive approaches. Specifically, a more data driven approach was taken during coding and themes definition, while a more inductive approach was followed during writing and contextualization with existing literature (Clarke \& Braun, 2013; Joffe, 2011). Saturation was reached when the coding process was no longer adding to the existing categorization (Guest et al., 2006). During the analysis, trustworthiness and credibility was assured using different strategies. This included prolonged engagement with data (the analysis took approximately 6 months since the generation of initial codes to final themes), periodic team discussion with two peer debriefers (bi-monthly meetings during a 3-month period), development of coding schemes and themes diagrams, in vivo coding and use of the interviewees excerpts when describing themes (Creswell, 2003; Glaser, 1978; Nowell et al., 2017). Data management and reporting themes were conducted using the software NVivo12.

\section{Results}

Three major themes emerged when regarding the main implications of the pandemic and confinement measures on $\mathrm{RC}$ dynamics and relations. These themes address 3 distinctive temporal dimensions of the 1 st lockdown experience lived during 2020: (i) chaos, novelty and organization (from March 15 to the beginning of April); (ii) reinventing normalization (April-May 2020); and (iii) deconfinement (from the end of May until July). These three themes were present in the discourse of all participants. Table 1 displays a synthesis of the codes, organized according to difficulties, challenges, and strengths, resulting from distinctive levels of perceived uncertainty, security and normalization lived in RC settings. Quotations were included for illustrating 
Table 1 Themes organized according to difficulties, challenges, and strengths/gains

\begin{tabular}{|c|c|c|c|}
\hline Themes & Chaos, novelty and organization & Reinventing normalization & Deconfinement \\
\hline \multicolumn{4}{|l|}{ Levels } \\
\hline Difficulties & $\begin{array}{l}\text { Increasing anxiety } \\
\text { Feelings of isolation } \\
\text { Delay in the provision of materials } \\
\text { Absence/extemporaneous guidelines }\end{array}$ & $\begin{array}{l}\text { Deteriorating relationships between staff } \\
\text { Work overload }\end{array}$ & $\begin{array}{l}\text { Absence of clear information } \\
\text { regarding procedures } \\
\text { Returning to uncertainty } \\
\text { as the home opens to the } \\
\text { exterior } \\
\text { Staff fatigue }\end{array}$ \\
\hline Challenges & $\begin{array}{l}\text { Develop and implement a contingency plan } \\
\text { Work organization and management of human } \\
\text { resources } \\
\text { Providing conditions for school online attendance } \\
\text { Organization of spaces/dynamics } \\
\text { Preventing staff burnout }\end{array}$ & $\begin{array}{l}\text { Creativity and flexibility } \\
\text { Reinforcing bonds } \\
\text { At distance school as an opportunity }\end{array}$ & $\begin{array}{l}\text { Psychoeducation with } \\
\text { families } \\
\text { Reestablishing previous staff } \\
\text { functions } \\
\text { Educating youth with health } \\
\text { preserving behaviors } \\
\text { Preparing a possible second } \\
\text { wave }\end{array}$ \\
\hline Strengths/Gains & $\begin{array}{l}\text { Involvement of civil society and municipality } \\
\text { Involving staff/child/youth in decision-making } \\
\text { Maintaining open communication channels with } \\
\text { family } \\
\text { Compromise and mission }\end{array}$ & $\begin{array}{l}\text { Feeling together/Cohesion in confronting } \\
\text { COVID } \\
\text { Recognition of youth "bravery" } \\
\text { Youth recognition of the staff commit- } \\
\text { ted role } \\
\text { Responsiveness and cooperation from } \\
\text { external institutions }\end{array}$ & $\begin{array}{l}\text { Learning from the experience } \\
\text { Reinventing vacations }\end{array}$ \\
\hline
\end{tabular}

Temporal unfolding

themes. Participants are identified with an alphanumeric code (Int_number of the interview).

\section{Theme 1: Chaos, Novelty and Organization (from March 15 to the Beginning of April)}

This theme results from participants' representation of panic, distress, and feelings of isolation in the face of completely new and "scary" events, but also from the need to face work organizational challenges. Isolation was felt because of the lack of social recognition of the challenging times institutions were facing and the absence of guidelines adjusted to youth RC settings.

Nobody talked about them ... they talked about the elderly, they talked about the prisoners, but nobody talked about youth in RC. Nobody spoke, nobody worried ... On top of that, they are young people full of life, deprived of being full time with their families and they see that time even more reduced. (Int_5)

Difficulties in obtaining timely responses from national health services namely, to respond to specific concerns about possible COVID infections, the provision of masks or other protection material, or health services provision, as in the mental health domain, were particularly highlighted by the interviewees.

It was very complicated to articulate with the health sector and we are talking, for example, about young people who take chronic medication, who have chronic or mental health problems and who are followed up in pediatric psychiatry, who have nothing to do with COVID, (...) we didn't have it, I'm not talking about follow-up appointments, I'm talking about medication. (I_17)

Although it was relatively consensual the lack of comprehensive and on-time guidelines from children/youth protection services, flaws in inter-institutional communication were differently evaluated by the interviewees.

we also had the Social Security Institution on our back

(...) this also ends up supporting us and knowing that,

if necessary, there is someone else who can help us.

(Int_11)

Additionally, responses from other local organizations such as the municipality, civil protection, but also from the civil society and the community, were highlighted as crucial for responding to stressful events. For example, in some cases, the wave of solidarity during the pandemic was responsible for supplying much needed computers for the adaptation to distance learning modalities, fast food for a "different dinner", or other important resources as two new vans.

A major challenge of this phase was to develop and implement a contingency plan and work organization that included decisions regarding the management of human resources (shifts, teams, and working in "mirror" procedures 
for preventing infections between shifts), reorganization and declutter of spaces and materials (namely quarantine rooms in case of infection, new entrances or returns resulting from house escapes or returning from home), arranging spaces for studying and assisting classes, and getting additional internet capacity. This was experienced as particularly challenging. The high staff turnover was heightened during this period, due to prophylactic leaves for workers with health preconditions, family assistance, or, in a very few cases, to precipitated resignations.

What I already identified as the team's weaknesses, and potentialities too $(\ldots)$ were more noticeable at this point. For example, I had two layoffs at this stage, from the educational team, which reflect this pressure. They were collaborators who were no longer (emotionally) well, it was not just the context of a pandemic. (Int_14)

Additionally, the increased workload resulted also from the duplication of tasks, namely in assisting and monitoring learning activities, as well as communicating with the school. The relationship with school teachers and directors was, for some directors, extremely tense in this first moment. According to the interviewees, the school demands weren't adapted either to the RC reality or to youngsters with learning disabilities and entitled to special educational curricula. In some RC facilities, children, and youngsters with these needs represent $80 \%$ of the residents.

The ability to respond to such unprecedented challenges in RC living was felt differently considering pre-existing conditions. Teams that, before the COVID pandemic, had a greater number of human resources or high levels of team cohesion, empathic concern, and close and significant bonds with children/youth, seem to reflect upon this experience, after this moment of chaos, as an opportunity to be closer, to connect, and to see the other.

If people gave it (being emotionally involved), it was because they had it to give, maybe there has never been such a demanding time before that it forced us to go and get it (...) We were contaminated with what each of us has to offer to the other and that was extraordinary. (Int_2)

Processes underlying rearrangements in work organizations were differently conducted and also differently felt by the teams. Some interviewees stressed the importance of involving all staff in work organization (e.g., working days and days off; duration of the shift per day/week/month; assisting school activities). This implied that in some cases there was a very horizontal debate that resulted in buttonup decisions, creating new opportunities for collaboration, sometimes resulting in blurring differences between the technical and the educative staff. Although the potential for conflict between staff was acknowledged, interviewees underlined the need to hold together as a team for confronting the pandemic.

The boundary between technical and educational (team) became more blurred (...) we are more partners and our language made us closer (...) everything was negotiated ... even the schedules were negotiated. (Int_9)

The interruption of that previous tasks, as jurisdictional reports, home visit arrangements, and other external routines allowed for an increased number of opportunities for "being together" and to be "focused on youth". Also, the idea that this period required involving all staff from the house was, for some of the interviewees, a strategy for surviving confinement: We could not do this without listening to everybody (...) people felt listened to and counted on. But this is not only important in the COVID phase, it is always important. People have very important things to say, very important.

Involving children/youth in decision making, empowering their voices, was felt as crucial for psychosocial adjustment during this adaptation process.

And all this helped them to feel at home (...) to make them more comfortable, to let them participate in things and make decisions, to let them get involved in the routines and in the decisions of the house. (This) help them, facilitate their integration, their routines, increase negotiation. (Int_3)

In other cases, decision and work organization seemed to be more hierarchized as a result of different coordination and leadership styles, which seem to be intrinsically associated with a broader definition of the role of RC and the organization's mission. In some of the cases, concentrating decisions and responsibilities implied work overload, exhaustion, and burnout complaints.

Months have been intense. (...) The biggest problem here was the scarcity of human resources because the teams are already small and the level of distress is greater. This was our main battle, the human resources. The team is afraid of a second wave, we all are as a society, but we are afraid that we will not be able to endure here in terms of working conditions. (Int_16)

Similarly, the house, the outdoor space and the possibilities to be creative in using spaces can be regarded as an additional facilitator/constrainer. These contrasting narratives are anecdotal examples of that.

the house doesn't have a lot of space, it doesn't have outside space... it was a huge barrier, it's just cell phones, watching Netflix and everything was managed around this. (Int_12) 
we had to create an environment that was as pleasant as possible internally and, on their leadership, we started doing things. Between parties, gastronomy to choose from, lots of barbecues, camping, swimming pools, it seems that they are in a seaside resort, things went on. (Int_20)

The main strategy adopted for responding to one of the most important implications of the confinement-i.e., the interruption of "being present" with the most significant ones-was to involve families in decisional processes. A path that was facilitated by a shared conviction of the team regarding the best interest of the child and youth. Facing novelty also included increasing the use of alternative channels of communication with families and other relatives to reinforce bonds and reassure families.

They (parents) felt that the children were doing well, they had this assurance of knowing that they were doing well, (...) and they felt it themselves too. (Int_20)

Additionally, for some interviewees, this experience seemed to contribute to heightening trust and perspectivetaking between families and RC professionals: It was a gratifying work with some families, (...) I think that in this context we all end up understanding each other a lot more, for being humbler and to understand the other side. (Int_1).

A close articulation with family needs during confinement, as the provision of essential goods, were also main concerns for assuring normalcy and youngsters' emotional stability. In few cases, face-to-face meetings with families, respecting distancing rules, were conducted earlier as a harm reduction strategy for preventing psychological crisis and maladjustments.

I don't know how we can do it, but I think that there are changes in family's life when they are very important, I don't know if in the case of the RC facilities this [physical contact] should be $100 \%$ blocked. (...) I think there should be different levels or different degrees of harm here. (Int_12)

The way interviewees expressed how they managed COVID is strongly related to an internalized sense of being deeply committed to children's/youth's wellbeing and with a sense of mission that empowered them to overcome obstacles. This irreplaceable feeling results from the perception that finding alternative and adequate responses, namely for youth with fragile or inexistent safe networks outside the institution, would be difficult.

There was also the feeling here of almost embracing this as a moment of mission, when people did not turn their backs to this situation, and I think that [this has] later reflected a lot in kids' stability. (Int_15)
To feel a huge concern and if we get infected and have to go home, who will replace us, who will take care of them? (Int_18)

This "human" commitment nurtures a tenuous border between personal and professional lives, with perceived gains for youth, but also with increased risks of burden and exhaustion. In some cases, some interviewees expressed how this was felt like a choice between "the kids" and $m y$ son/daughter, my dad/mum. In other cases, "choosing" the interviewees' family was felt akin to abandon, to leave the kids, to run away. Consequently, they felt that there was no choice to be made, contrarily to other mothers and fathers that left their work to assist their own children without internal conflict:

feeling that we, unlike other parents, could not leave. The other parents had this right to leave and come home and be with their children; we, as a duty to those young people, could not do it. It was not legitimate if we all abandoned the house (...) in the beginning we were angry too, for not enjoying the same right as other parents. (Int_7)

\section{Theme 2: Reinventing Normalization (April-May 2020)}

Creativity and flexibility progressively took the place of crisis management, logistic decisions, and aseptic preoccupation or, in extremis, the deepest fear to close up due to the absence or insufficient human resources. Reinventing normalization during extreme situations and conditions is a very interesting context for observing homes' plasticity and analyzing principles of intervention. The increased sense of security that resulted from reasoning that after all, we are doing things right, gave space for some of the institutions to advocate that living and working in $\mathrm{RC}$ has implications in the way people experience confinement.

These girls were always closed in the house without seeing anyone. The school brought greater anxiety, tremendous instability (...) There was a need here to say, it's over! In the other years, we adapted to school demands, these weeks the school will have to adapt to us. (Int_5)

This second moment is extrinsically associated with the process of either reinforcing bonds or, on the contrary, deteriorating relations. The dominant narrative was on how "incredibly" and "unexpectedly" youth face confinement: the kids were very brave, they were the real heroes, we have discovered another facet of them, and I think they discovered us, too. (Int_18). 
Facing crisis as a collective aim seemed also to have contributed to heightening cohesion and bonds between youth and teams.

Reinforced the bonds between people... people got to know each other better (...) this has to bring something new, it has to add something, but I dare to say that there was already that predisposition, there was already raw material here to cook this soup. But it was a very, very good thing, very good ... this connection was very important, and this does not go unnoticed for the young people. (Int_2)

For some, this period of calmness but also creativity was also a result of a cluster of conditions that seem to have narrowed the differences between youth. The perception that in this situation some staff could choose not to be at work, as well as the interpersonal dynamics that resulted from confinement, fostered perspective-taking and group cohesion.

[The most positive thing] it was the knowledge of the other, the relationship in this sense of the development of one's own with knowledge of the other as well. Children got to know their friends better and with this, they also got to know themselves better too. (Int_17)

This process was also felt as an insightful path for prioritizing the importance of being close, to embrace the other:

This is very complicated for the girls who are here and for us as well, because our home is a home, in terms of affection and showing physical affection is quite important. We hug each other, we give lap, we touch and suddenly we are no longer able. (Int_5)

A TD proudly told an episode where a young boy suddenly expressed missing physical comfort, by "threatening" with the expression: "Ah you will see when I hug you again!". Also, for some directors, the absence of family visits or weekend visits seems to blur one of the important differences between the children, namely that some usually had the opportunity to have family contacts, while others did not. In some cases, family visits contributed to psychological adjustment and emotional regulation, even if sometimes requiring exceptional measures as previously developed. But for other interviewees, youth acknowledgment that family visit interruption was not attributable to family decisions, but to an external factor common to all, was associated with fewer interpersonal conflicts and behavioral problems. To be sure, the fact that youngsters did not need to deal with the fact that parents or other relatives weren't coming to the visit when others did, seemed to have contributed to a more equitable environment.

COVID turns them all equal. They didn't go home, because the court judged that the mother or parents were not competent, or they weren't going because ... it was because the situation was the same for everyone. (Int_7)

This second phase was also related to how the external environment and institutions adapted to the pandemic. Institutions that directly work with RC facilities were, according to the interviewees, more responsive and cooperative. Health, social services, and jurisdictional sectors were more rapid and efficacious in responding. School workload was progressively reduced, and, for some institutions, this meant the possibility to successfully adapt to distant learning. In some cases, this has even been associated with higher levels of investment and school performance. According to the interviewees, reasons to explain the additional success might lie in the individualized attention provided by RC staff during school activities and class monitorization, the absence of distressing factors in peer interactions, and less selective attention on behavior problems.

She had a terrible relationship with the school that didn't give her enough space to have peace for knowledge and to look at it with calm and eyes to understand: let me see what I know, what I don't know, what I can improve. There was no such tranquility because she was always fighting. (Int_7)

If in these cases, distance education seems to be evaluated as a possible alternative for children/youth under care beyond imposed confinement, in other cases, distance education was not perceived as an advantage, namely in cases where being apart from school, peers and teachers, were an additional challenge for psychological adjustment. This was particularly evident in youth that had fewer learning settings conditions and resources in the RC setting, and for youth that benefited from alternative educational activities and therapies that were abruptly interrupted.

\section{Theme 3: Deconfinement (End of May-July)}

Apparent normalization was progressively challenged by a third moment, corresponding to the final temporal category that came with the termination of the lockdown.

The third moment arrived when by looking through the window they felt they were the only ones in lockdown, when they started to hear about opening, it all came up again. The $R C$ was among the last social responses that had information about deconfinement (Int_9). For some TD this process was also felt as not being properly monitored by RC institutions, introducing disparities between youth that were living in different RC facilities and ultimately when comparing with youth that were not living in RC. This process was conducted according to guidelines from the health and 
social sectors, with distinctive moments and strategies. For most of the RC facilities, before restoring previous family visits or overnight stays, families were allowed for visits in open spaces (in cases where there were outside facilities), then progressively youth started to go home. In some cases, this moment implied different challenges: how am I going to tell a mother who wasn't with her child for two and a half months that she cannot give hugs and kisses? (Int_19). For some TD this process was lived with preoccupation and anguish. Opening the house was perceived as a loss of control and the returning of uncertainty, namely in RC settings that had already experienced having children and youth with the virus.

And then the 'anxiety to leave' phase, the lack of definition. How were we going to let them out without controlling the steps they took outside, who they were going to be with? It was another challenge. They didn't accept it, they started to see people passing by on the street because they already seen their friends, they already went out, there was no control (...). This also brought us anguish (...) we tried to extend this as much as possible. (Int_11)

Opening the house also implied that youth had again to face the differences between them and others, namely in one of the most central domains of their lives: their relationship with family and other relatives.

They were all in the same boat, in the same situation. Undoubtedly, when this situation opened, the differentiation factor entered again, and I (the youth) am obliged to look at my difference. And then came the individual issues, the shadow of each one, that darker side of each one. And we started to have those more intense conflicts, which had been diluted in the pandemic. Now I start to have already that young man who is angry, it is with his parents, and he cannot verbalize it and unloads it on his colleagues. (Int_7)

With deconfinement also came the anticipation of a second wave and the reflection upon the home plasticity in dealing with possible upcoming events. Some TD expressed the anguish of not being able to get through a second wave, namely considering the difficulties in managing human resources during this period and dealing with new entrances and work unfolding.

Additionally, longer shifts and the attribution of distinctive roles to members of the educative team, namely for supporting school activities, were identified as being additional stressors against team cohesion:

In addition to the overload... when we return to work without working in different [separate] teams at some point seems that there is a team and there is another one. (Int_6)

Other interviewees anticipated that they will be less enthusiastic but more prepared and strengthened (II) in case there is a 2nd lockdown, namely because this exceptional moment reinforced strategies for work organization and decision making, through the creation of more space and time opportunities for involving youth and staff. Additionally, the increased perception that there are decisions that cannot be anticipated and that the situation should be monitored daily, were a contribution in dealing with the uncertainty and unpredictability that came with the pandemic.

A concern at a time, do not add concerns to those we already have every day. (...) Let things flow. At every moment we will have to find an answer because that is how we manage to live; otherwise, we cannot live ... neither with fear nor panic (...) there's no use of being in a panic, there's no time for that. (Int_3)

This was enhanced by reflective thinking on the main implications of these strange days on RC house's dynamics. This reflexive stance was perceived by some as an opportunity, after the 'chaos' enhanced by the panic of the uncertainty of the 1st phase: the COVID forced us to look at what daily passed us by a little unnoticed. (Int_14).

Additionally, most of the teams were revealing signs of fatigue and tiredness, associated with shift changes introduced by the contingency plan, but also with the absence or reduction on vacation periods. In some cases, TD deconfinement implied a parallel process of teams and shifts reorganization to enable staff vacations and restoring periods of rest and less demanding workflows. Furthermore, deconfinement implied planning vacations for youngsters according to the new rules required by the pandemic, outside activities in nature, or renting a house delimited to the people from a specific RC facility. This moment was still open to upcoming challenges.

\section{Discussion}

These adverse contexts, such as the pandemic, managed to make some of the weaknesses that we already had in place more visible, but they also surprised us regarding the resistance, the resilience of both the team and the young people. (Int_14).

The main aim of this study was to analyze how $\mathrm{RC}$ facilities in Portugal have experienced and managed the confinement during the 1 st pandemic lockdown. Considering the profound changes in services provision in RC settings, with the most visible one being the interruption of children's/ youth's family/relatives visits, this context offered peculiar 
conditions for understanding crisis management and gaining a deeper knowledge on the broader and systemic functioning of RC. This study is also particularly relevant for comprehending the role of vulnerability when addressing risk, inside and between RC settings. Also, by acknowledging implications on circumstantial and structural levels, this study could be particularly relevant for professionals and decision makers working on child welfare domain.

Considering the exploratory nature of the study, the gap in the literature on this domain, and the potential of a qualitative approach for gaining a deeper knowledge on services' responses and processes (Vindrola-Prados et al., 2020), 20 interviews were conducted with professionals that have been responsible for decision making and managing "the boat to safe shore". During the thematic analysis, 3 major themes emerged: chaos, novelty and organization, reinventing normalization, and deconfinement. The themes address different approaches to the interviewees' representations on how this period was experienced, informed decision making, and resulted in complex changes in house dynamics. The themes also address distinctive patterns regarding communalities and consensus between participants. Given that this distinctive path could be intrinsically associated with $\mathrm{RC}$ regular functioning, this analysis has focused on how this experience has extended prior difficulties and challenges and ultimately contributed to shedding a light into the "black box" state of knowledge on processes associated with different outcomes in RC (Leipoldt et al., 2019).

During the first theme, it was consensually expressed by the interviewees how this unprecedented experience was felt like an extreme and challenging stressor for the RC dynamics. The perception of the absence of specific guidelines and responses from sectors that directly work in child welfare, the unexpected reduction of human resources and the anguish due to the possibility of closing, seemed to heighten a sense of isolation and of not being fully understood about what it means to work and live in RC. If "being alone in this process" encompasses the narratives of professionals that assume management roles in RC during the pandemic, during this time this perception seems to activate a sense of mission with distinctive implications for the team dynamics, youth under care and for the professionals' balance of professional and personal lives. First, this result requires close attention to this feeling of isolation and of not being recognized as a front-line worker that "battles" in children/youth welfare. The paradox that emerges from the complexity and demanding nature of the task (Hicks et al., 1998) and the lack of knowledge and confidence in RC (Colton \& Roberts, 2006), seems to prevent a comprehensive and discriminative analysis of the factors that contribute to more secure care responses. These facilitators were more visible during the second theme. The ability to develop normalization processes in extreme situations was comprehended as being intrinsically associated with the (non)ability of the team to respond and work congruently to protect the youth that was unequally facing additional emotional challenges in lockdown. In some cases, the opportunity to make a difference, to feel of being part of a shared goal 'to protect youth', and the recognition of their distinctive role resulted in individual self-worth process, team cohesion and a closer bond with youth. In other cases, this challenging time precipitated resignations and emotional distress and incremented conflicts in the team, contributing to the increase of professional's mobility. High staff turnover seems to be one of the greater problems of the RC, constituting one of the major obstacles for the creation of a secure and healing environment for youth. Poor working conditions and the challenging task to respond to pain-based behaviors (Anglin, 2004), as well as increasingly complex and behavioral problems, seem to contribute to the perception of this profession as a short-term career choice (Colton \& Roberts, 2006). If it is clear the harmful impact of high mobility in RC, namely during crisis management, both these outcomes address the importance to work with, what Colton and Roberts (2006) called a disempowered staff and on the emotional distress risks for professionals working in these settings (Audin et al., 2018). The sense of commitment and mission in assisting children/youth (Rycraft, 1994) seems to be closely connected to the perception that benefitting from family assistance or from prophylactic isolation leaves, meant a difficult choice between family and personal health, on the one hand, and the children/ youth, on the other. This ambivalence of the "choice" can be understood as a sign of the emotional bond and genuine interest for youth under care. Nevertheless, psychological responses of health frontline workers on previous pandemic outbreaks stress the long last effect of stress, anxiety and depression symptoms (Lee et al., 2007), resulting also from this non-experienced choice. The intrinsic belief of 'not being the one who will abandon', can be particularly distressing and work as an additional stressor for burnout, compromising the emotional availability to provide a secure base and safe haven care (Barton, 2012; Graham, 2005; Mota \& Matos, 2016). Furthermore, in this case, the felt perception of scarce adequate human resources and responses could heighten the feeling of hardly being "replaceable".

This process also involved different reflections on the main facilitators for restoring a sense of normalization. For some interviewees, involving youth and all staff members in decision making was crucial for dealing with the emotional distress associated with the confinement measures and to heighten an extra familiar social climate (Anglin, 2004), both for youth and professionals. In other cases, namely in situations where the interviewees gave greater relevancy in their narrative to the scarcity of human resources and to team's conflicts, a more autocratic and overburdened decision-making was more explicit. If this result addresses 
the systemic nature of out-of-home care, by stressing the relevance of management styles and leadership on house dynamics (for a comprehensive analysis see Clough \& Ward, 2006), it is not clear if this leadership path during crises is a result or a consequence of prior RC dynamics. A comprehensive analysis of the motives underlying staff and youth level of involvement in house decisions, vastly advocated by international organizations and by research (Magalhães et al., 2018; UNCRC, 1989), also requires greater attention to RC structural conditions.

A second result worthy of reflection regards the interviewee's perception of how this moment gathered, almost arbitrarily, the necessary conditions for empathy, perspective-taking, and attention to the extra familiar social environment. For some, being released from bureaucratic tasks and to spend more time "in relation", whether in support for school activities or engagement in ludic initiatives, was crucial for achieving synchrony and congruence. Additionally, the affective resonance in assisting staff involvement seems to fuel one of the most important and challenging tasks of professionals working in $\mathrm{RC}$ settings, that is, to induce in youth a sense of worth of love and affection (Graham, 2005). The challenge is to intentionalize this emotional availability as a central interventional strategy and to advocate for the importance of creating conditions for a real "culture of caring" (Ainsworth \& Fulcher, 2008, p. 151).

This study stresses how this experience could heighten the systemic fragilities of RC responses. Promoting a secure and healing environment for children/youth also requires a closer look at the challenges that emerge during unprecedented crisis management, such as the pandemic and consequent lockdown, but also how these challenges extend prior challenges and difficulties. Addressing structural constraints, namely mobility of human resources, scarcity of supportive networks, and fragilities in providing comprehensive and integrative care, can be crucial to inform best practices and to enhance a therapeutic environment that could be able to provide "treatment, education, socialization, support, and protection" (Whittaker et al., 2016, p. 24).

The major contribution of the study relates to its ability for gaining knowledge on a very pressing and current phenomenon and ultimately to contribute for informing preventative measures during the pandemic or other crises in child welfare. Nevertheless, there are some limitations worth to be mentioned. Although the use of qualitative methods allowed for a comprehensive analysis of a complex phenomenon still under explored in the literature (Johnson \& Onwuegbuzie, 2004) and especially relevant for exploring the pandemic impact on people's lives (Vindrola-Prados, et al., 2020), it prevents results' generalization. Additionally, the fact that the intervieews were also involved in a larger research project could induce social desirability bias.
The decision of involving directors as key informants in the study was justified for addressing challenges imposed by confinement to decision making and management decisions. Although we consider a research duty to involve youth in knowledge production that directly affects their lives, inducing reflection on potential distressing themes that youth were facing at that current time, could contribute to heightening the distressing nature of the experience. Nevertheless, a systemic and comprehensive analysis of the phenomena should involve in the future other key informants, as youth, family members and other elements of the teams working in RC facilities.

\section{Recommendations for Practice and Policy}

The negative impacts of $\mathrm{RC}$ on youth development have been consistently reported (van Ijzendoorn et al., 2011). Deficits in physical resources, unstable staffing patterns and inadequate caregiver-child interactions may result in exposure to "structural neglect" (van Ijzendoorn et al., 2011), imposing additional challenges to children and youth that have already been exposed to adversity (Thoburn \& Featherstone, 2019). Nevertheless, there seems to be an important variability in the quality of care and protection provided by RC and consequent outcomes (Costa et al., 2019). In this sense, this research can be an important contribution to disentangle factors that sustain distinctive practices and organizational dynamics in the continuum of care (Anglin, 2004). Additionally, problematizing challenges in youth RC settings from a systemic and organizational perspective, could be particularly relevant for informing the debate about the RC level of specialization and adequacy in child welfare policies.

This research stressed five main topics that could be particularly relevant for informing future guidelines for managing RC during crisis episodes or to strengthen a broader and regular functioning. The first topic regards the importance for supporting professional practices and empowering people that work and live in $\mathrm{RC}$ facilities, namely by preventing feelings of loneliness and non-recognition. During exceptional times, a crisis team would be particularly relevant for assuring contingent guidelines and support. Given the complexity of the task underlying managing decisions, a multidisciplinary team composed by professionals from the health, educational, social and jurisdictional sectors, would be particularly useful. Supportive practices could assume distinctive modalities - such as supervision groups, informative sessions and individual support for implementing guidelines-and periodicities, according to staff needs and the challenging nature of the task.

A second topic reflects the relevance to address staff retention in youth RC. Mobility was for some RC facilities heightened during confinement; nevertheless, this seems to be a key and ever-present issue on children's welfare 
worldwide (Colton \& Roberts, 2006). Research has stressed low work status, poor salaries, insufficient training, difficulties in coping with challenging behaviors and compassion fatigue, as important determinates of staff mobility (Audin et al., 2018; Colton \& Roberts, 2006). Considering this, child welfare policies should address work conditions as important predictors of quality of care, and, together with supportive practices, prevent mobility.

The third topic addresses the usefulness of considering distance education in particular cases and for specific periods as a complementary method to traditional educational settings (Hebebci et al., 2020). This reflection emerged from the acknowledgment that this modality could enhance performance and psychosocial adjustment, namely in cases where going to school could be particularly overwhelming and result in iatrogenic effects (e.g., absenteeism, bullying or psychosocial maladjustment). The implementation of this alternative learning method would imply a close and monitored articulation between school, youth, and the RC professionals responsible for supporting learning activities.

The fourth topic addresses the need to involve children/ youth in decision-making processes considering RC life. Confinement allowed, in some of the cases, to hear and to recognize youth's ability to develop activities with important consequences in house dynamics. During this experience, most directors expressed how incredible, how surprising, how brave children/youth faced the confinement and how inspirational they were. Acknowledging the motives and conditions underlying youth enthusiastic involvement could be particularly relevant for expanding youth voices in RC.

The fifth topic regards the need to consider the multiple implications of the restriction and lockdown measures when addressing risk in vulnerable populations. Restricting visits and physical contact with families/relatives can be an additional stressful event with important implications for children's/youth's mental health and psychosocial development. Some of the intervieews adopted a harm reduction strategy for addressing those risks, but to what extent there are uncountable long last effects of social distancing, particularly from significative and attachment figures? How does this distancing compromises/challenges the work conducted with children and families? Although knowledge production on the pandemic impact on youth out-of-care is still scarce, research has been addressing the morbidity resulting from social distancing, restriction measures, and changes in service provision, namely substance use, suicidal ideation and worsen psychopathological indicators in vulnerable populations (Czeisler et al., 2020; Thomson et al., 2020; UN, 2020). The harmful impact of the epidemic will be unequally distributed namely in children/youth already in vulnerable situations (UN, 2020), making it necessary to extend the evaluation of risk and impairment besides strict medical condition indicators. Also, the present research addressed distinctive organizational and human/material resources that seem to act as protective factors for dealing with the pandemic uncertainty and harmful impacts of restrictive measures between institutions. There is an urgent need to redefine vulnerability (Lancet, 2020), inside and between youth RC settings, to prevent iatrogenic effects of public health responses. If we fail in identifying vulnerability, "the consequences of this pandemic will be even more devastating" (Lancet, 2020, p. 1089).

\section{Conclusions}

There is a large consensus that "removing a child from their parents should be a measure of last resort" (UN, 2010), and that improving quality of care requires a comprehensive and ecological analysis of the major determinants that contribute to children's/youth's psychosocial well-being. Considering the complexity and diversity of outcomes that comprehend the continuum of care services (Anglin, 2004), research should bridge the gap between practices and child welfare policies, using inclusive methodologies, bottom-up approaches (Wessells, 2015), involving people whose lives are closely depending on that, namely youth, families, and professionals. The pandemic allows us to reflect upon structural out-of-home care fragilities that should be considered in current child welfare reforms, but also to alert us to the important balance that should be conducted between risk and mitigation measures, namely in vulnerable populations as children and youth in out-of-home care (Thomson et al., 2020; UN, 2020).

Funding Portuguese national funding agency (FCT) funded this work (PTDC/PSI-ESP/28653/2017.

\section{Declarations}

Conflict of interest We have no conflict of interest to disclose.

\section{References}

Ahmed, F., Ahmed, N., Pissarides, C., \& Stiglitz, J. (2020). Why inequality could spread COVID-19. Lancet Public Health, 5(5), e240. https://doi.org/10.1016/s2468-2667(20)30085-2

Ainsworth, F., \& Fulcher, L. (2008). Chapter 7. Creating and sustaining a culture of group care. Child \& Youth Services, 28, 151-176. https://doi.org/10.1300/J024v28n01_01

Anglin, J. P. (2004). Creating "well-functioning" residential care and defining its place in a system of care. Child and Youth Care Forum, 33(3), 175-192. https://doi.org/10.1023/B:CCAR.00000 29689.70611.0f 
Audin, K., Burke, J., \& Ivtzan, I. (2018). Compassion fatigue, compassion satisfaction and work engagement in residential child care. The Scottish Journal of Residential Child Care, 17(3), 5-27.

Barton, S., Gonzalez, R., \& Tomlinson, P. (2012). Therapeutic residential care for children: An attachment and trauma-informed model for practice. Jessica Kingsley Publishers.

Braun, V., \& Clarke, V. (2006). Using thematic analysis in psychology. Qualitative Research in Psychology, 3(2), 77-101. https://doi.org/ 10.1191/1478088706qp063oa

Clarke, V., \& Braun, V. (2013). Teaching thematic analysis: Overcoming challenges and developing strategies for effective learning. The Psychologist, 26, 120-123.

Clough, R., Bullock, R., \& Ward, A. (2006). What works in residential child care: A review of research evidence and the practical considerations. National Children's Bureau.

Colton, M., \& Roberts, S. (2006). Factors that contribute to high turnover among residential child care staff. Child \& Family Social Work, 12(2), 133-142. https://doi.org/10.1111/j.1365-2206.2006. 00451.x

Costa, M., Mota, C. P., \& Matos, P. M. (2019). Predictors of psychosocial adjustment in adolescents in residential care: A systematic review. Child Care in Practice. https://doi.org/10.1080/13575279. 2019.1680533

Courtney, D., Watson, P., Battaglia, M., Mulsant, B. H., \& Szatmari, P. (2020). COVID-19 impacts on child and youth anxiety and depression: Challenges and opportunities. The Canadian Journal of Psychiatry, 65(10), 688-691. https://doi.org/10.1177/07067 43720935646

Creswell, J. W. (2003). Research design: Qualitative, quantitative, and mixed method approaches. Sage Publications.

Czeisler, M. É., Lane, R. I., Petrosky, E., Wiley, J. F., Christensen, A., Njai, R., Weaver, M. D., Robbins, R., Facer-Childs, E. R., Barger, L. K., Czeisler, C. A., Howard, M. E., \& Rajaratnam, S. (2020). Mental health, substance use, and suicidal ideation during the COVID-19 Pandemic-United States, June 24-30, 2020. Morbidity and Mortality Weekly Report, 69(32), 1049-1057.

Delgado, P., \& Gersão, E. (2018). O acolhimento de crianças e jovens no novo quadro legal: Novos discursos, novas práticas? [Foster care in the new legal framework: New speeches, new practices?]. Análise Social. https://doi.org/10.31447/AS00032573.2018226.05

Dong, L., \& Bouey, J. (2020). Public mental health crisis during COVID-19 pandemic, China. Emerging Infectious Disease Journal, 26(7), 1616. https://doi.org/10.3201/eid2607.200407

Galvin, M., \& Kaltner, M. (2020). Understanding the impact of covid19 on out-of-home care in Australia. Ernest \& Young.

Glaser, B. G. (1978). Theoretical sensitivity. Sociology Press.

Goldman, P. S., van Ijzendoorn, M. H., Sonuga-Barke, E. J. S., Lancet Institutional Care Reform Commission Group. (2020). The implications of COVID-19 for the care of children living in residential institutions. The Lancet. Child \& Adolescent Health, 4(6), e12e12. https://doi.org/10.1016/S2352-4642(20)30130-9

Graham, G. (2005). Attachment theory and wellbeing for the young person in residential care: The provision of a second chance secure base for the child in crisis. Relational Child and Youth Care Practice, 19(1), 1-25.

Guest, G., Bunce, A., \& Johnson, L. (2006). How many interviews are enough? Field Methods, 18, 59-82. https://doi.org/10.1177/ 1525822 X05279903

Hebebci, M., Bertiz, Y., \& Alan, S. (2020). Investigation of views of students and teachers on distance education practices during the Coronavirus (COVID-19) pandemic. International Journal of Technology in Education and Science, 4, 267-282. https://doi.org/ 10.46328/ijtes.v4i4.113

Hicks, L., Archer, L., \& Whitaker, D. (1998). The prevailing cultures and staff dynamics in children's homes: Implications for training.
Social Work Education, 17(3), 361-373. https://doi.org/10.1080/ 02615479811220351

Ingram, S. (2020). Lives unpended: How COVID-19 threatens the futures of 600 million South Asian children. Retrieved from https://www.unicef.org/rosa/media/7946/file/UNICEFUpendedLi vesReport-June2020.pdf

Joffe, H. (2011). Thematic analysis. In D. Harper \& A. R. Thompson (Eds.), Qualitative research methods in mental health and psychotherapy (pp. 209-223). Wiley. https://doi.org/10.1002/97811 19973249.ch15

Johnson, R. B., \& Onwuegbuzie, A. J. (2004). Mixed methods research: A research paradigm whose time has come. Educational Researcher, 33(7), 14-26. https://doi.org/10.3102/0013189X03 3007014

Lancet, T. (2020). Redefining vulnerability in the era of COVID-19. Lancet, 395(10230), 1089-1089. https://doi.org/10.1016/S01406736(20)30757-1

Lee, A. M., Wong, J. G., McAlonan, G. M., Cheung, V., Cheung, C., Sham, P. C., Chu, C. M., Wong, P. C., Tsang, K. W., \& Chua, S. E. (2007). Stress and psychological distress among SARS survivors 1 year after the outbreak. Canadian Journal of Psychiatry, 52(4), 233-240. https://doi.org/10.1177/070674370705200405

Leipoldt, J. D., Harder, A. T., Kayed, N. S., Grietens, H., \& Rimehaug, T. (2019). Determinants and outcomes of social climate in therapeutic residential youth care: A systematic review. Children and Youth Services Review, 99, 429-440. https://doi.org/10.1016/j. childyouth.2019.02.010

Magalhães, E., Calheiros, M. M., \& Antunes, C. (2018). 'I always say what I think': A rights-based approach of young people's psychosocial functioning in residential care. Child Indicators Research, 11(6), 1801-1816. https://doi.org/10.1007/s12187-017-9511-

Mota, C. P., \& Matos, P. M. (2016). Caregivers' attachment and mental health: Effects on perceived bond in institutional care. Professional Psychology: Research and Practice, 47(2), 110-119. https://doi.org/10.1037/pro0000047

NISS. (2020a). CASA 2019: Relatório de Caracterização Anual de Situação de Acolhimento das Crianças e Jovens. [HOME 2019: Annual Characterization Report on the Situation of Child and Youth in Care]. Retrieved from http://www.seg-social.pt/docum ents/10152/17405298/Relatório\%20CASA\%202019/0bf7ca2bd8a9-44d2-bff7-df1f111dc7ee

NISS. (2020b). COVID 19-Medidas de Apoio Excecional-Infância e Juventude-Versão 1. [COVID-19-Additional support measures to childhood and youth-Version 1]. Retrieved from https://backo ffice.ump.pt/files/files/Covid19_Planodeexecção_CA.pdf

NISS. (2020c). COVID 19-Medidas de Apoio Excecional-Infância e Juventude-Versão 3 [COVID-19-Additional support measures to childhood and youth-Version 3]. Retrieved from http://www. seg-social.pt/documents/10152/16722120/COVID+19_plano+ de+exceção+CA+V02+1+abril.pdf/f7df0b2f-05ac-498e-b9b9b6ce 5 f03ce $9 d$

NISS. (2020d). National Institute of Social Security. COVID 19Medidas de Apoio Excecional-Infância e Juventude-Versão 2 COVID-19. [COVID-19-Additional support measures to childhood and youth-Version 2]. Retrieved from http://www. seg-social.pt/documents/10152/16722120/COVID+19_+Acolh imento+Crianças + e+Jovens $+\% 28002 \% 29$.pdf/6ae43070-d8af47fc-a311-708c43441d0d

Nowell, L. S., Norris, J. M., White, D. E., \& Moules, N. J. (2017). Thematic analysis: Striving to meet the trustworthiness criteria. International Journal of Qualitative Methods, 16(1), 1609406917733847. https://doi.org/10.1177/1609406917733847

Patton, M. Q. (2002). Qualitative research and evaluation methods (3rd ed.). Sage Publications. 
Rajkumar, R. P. (2020). COVID-19 and mental health: A review of the existing literature. Asian Journal of Psychiatry, 52, 102066. https://doi.org/10.1016/j.ajp.2020.102066

Rycraft, J. R. (1994). The party isn't over: The agency role in the retention of public child welfare caseworkers. Social Work, 39(1), $75-80$.

Silliman Cohen, R. I., \& Bosk, E. A. (2020). Vulnerable youth and the COVID-19 pandemic. Pediatrics. https://doi.org/10.1542/peds. 2020-1306

Tarren-Sweeney, M. (2008). The mental health of children in outof-home care. Current Opinion in Psychiatry, 21(4), 345-349. https://doi.org/10.1097/YCO.0b013e32830321fa

Thoburn, J., \& Featherstone, B. (2019). Adoption, child rescue, maltreatment and poverty. In S. A. Webb (Ed.), The Routledge handbook of critical social work (pp. 401-411). Routledge.

Thomson, S., Doan, T., Liu, D., Schubert, K. O., Toh, J., Boyd, M. A., \& Galletly, C. (2020). Supporting the vulnerable: Developing a strategic community mental health response to the COVID-19 pandemic. Australasian Psychiatry, 28(5), 492-499. https://doi. org/10.1177/1039856220944701

UN. (2010). Guidelines for the Alternative Care of Children: Resolution/adopted by the General Assembly, 24 February 2010, A/ RES/64/142. Retrieved from https://www.refworld.org/docid/ $4 \mathrm{c} 3 \mathrm{acd} 162 . \mathrm{html}$

UN. (2020). Policy Brief: The Impact of COVID-19 on children. Retrieved from https://unsdg.un.org/sites/default/files/2020-04/ 160420_Covid_Children_Policy_Brief.pdf

UNCRC. (1989). UN Convention on the Rights of the Child (UNCRC). General Assembly resolution 44/25 of 20 November 1989. Retrieved from https://childrens-rights.digital/hintergrund/ UNKRK.cfm

van Ijzendoorn, M. H., Palacios, J., Sonuga-Barke, E. J. S., Gunnar, M. R., Vorria, P., McCall, R. B., LeMare, L., Bakermans-Kranenburg, M. J., Dobrova-Krol, N. A., \& Juffer, F. (2011). Children in institutional care: Delayed development and resilience. Monographs of the Society for Research in Child Development, 76(4), 8-30. https://doi.org/10.1111/j.1540-5834.2011.00626.x
Vindrola-Padros, C., Chisnall, G., Cooper, S., Dowrick, A., Djellouli, N., Symmons, S. M., Martin, S., Singleton, G., Vanderslott, S., Vera, N., \& Johnson, G. A. (2020). Carrying out rapid qualitative research during a pandemic: Emerging lessons from COVID-19. Qualitative Health Research, 30(14), 2192-2204. https://doi.org/ 10.1177/1049732320951526

Wessells, M. G. (2015). Bottom-up approaches to strengthening child protection systems: Placing children, families, and communities at the center. Child Abuse \& Neglect, 43, 8-21. https://doi.org/10. 1016/j.chiabu.2015.04.006

Whittaker, J. K., Holmes, L., del Valle, J. F., Ainsworth, F., Andreassen, T., Anglin, J., Bellonci, C., Berridge, D., Bravo, A., Canali, C., Courtney, M., Currey, L., Daly, D., Gilligan, R., Grietens, H., Harder, A., Holden, M., James, S., Kendrick, A., ... Zeira, A. (2016). Therapeutic residential care for children and youth: A consensus statement of the international work group on therapeutic residential care*. Residential Treatment for Children \& Youth, 33(2), 89-106. https://doi.org/10.1080/0886571X.2016.1215755

WHO. (2021). WHO coronavirus disease (COVID-19) dashboard. Retrieved March 18, 2021, from https://covid19. who.int/

Wilke, N. G., Howard, A. H., \& Goldman, P. (2020). Rapid return of children in residential care to family as a result of COVID-19: Scope, challenges, and recommendations. Child Abuse \& Neglect. https://doi.org/10.1016/j.chiabu.2020.104

Wong, C. A., Ming, D., Maslow, G., \& Gifford, E. J. (2020). Mitigating the impacts of the COVID-19 pandemic response on at-risk children. Pediatrics, 146(1), e20200973. https://doi.org/10.1542/ peds.2020-0973

Publisher's Note Springer Nature remains neutral with regard to jurisdictional claims in published maps and institutional affiliations. 